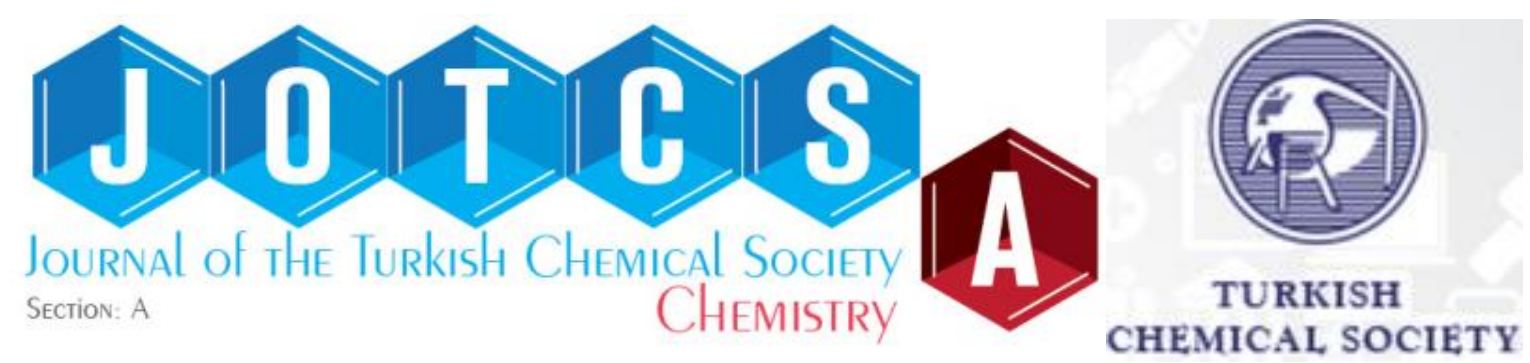

\title{
ENHANCED PHOTOCATALYTIC PROPERTIES OF Sn-DOPED ZnO NANOPARTICLES BY FLAME SPRAY PYROLYSIS UNDER UV LIGHT IRRADIATION
}

\author{
Metin Yurddaskal1,2 (D), Serdar Yildirim ${ }^{1,2}$ (D), Tuncay Dikici ${ }^{3}$, Melis Yurddaskal ${ }^{4}$, \\ ${\text { Mustafa } \text { Erol }^{3} \text { (D), Idil Aritman }}^{1,2}$ (D) and Erdal Celik ${ }^{2,5,6}$
}

(This article first appeared in PPM2017 and was accepted as a non-peer-reviewed manuscript to be published in JOTCSA)

${ }^{1}$ Dokuz Eylul University, The Graduate School of Natural and Applied Sciences, 35390, Izmir, Turkey

${ }^{2}$ Dokuz Eylul University, Center for Fabrication and Applications of Electronic Materials (EMUM), 35390, Izmir, Turkey

${ }^{3}$ Izmir Katip Celebi University, Department of Materials Science and Engineering, 35620, Izmir, Turkey

${ }^{4}$ Celal Bayar University, Department of Mechanical Engineering, 45140, Manisa, Turkey

${ }^{5}$ Dokuz Eylul University, Department of Metallurgical and Materials Engineering, 35390, Izmir, Turkey

${ }^{6}$ Dokuz Eylul University, Department of Nanoscience and Nanoengineering, 35390, Izmir, Turkey

Abstract: Zinc oxide ( $\mathrm{ZnO}$ ) is widely used in different areas thanks to its unique photocatalytic, optic and electrical properties. Sn doped ZnO nanoparticles were synthesized through flame spray pyrolysis (FSP) technique. The Sn dopant concentrations were 1, 3, 5, 7 and 9 at. \% in produced $\mathrm{ZnO}$ nanoparticles. The structural analysis of the produced powders was performed by X-Ray Diffraction (XRD) methods. The surface morphology and particle size distribution of the nanoparticles were identified using scanning electron microscopy (SEM), and dynamic light scattering (DLS) techniques. In addition to this, produced photocatalysts were evaluated for degradation of aqueous methylene blue (MB) solutions under UV light irradiation. Sn-doped nanoparticles have superior photocatalytic activity compared to un-doped ZnO.

Keywords: ZnO, Sn-doped, nanoparticles, photocatalysis, flame spray pyrolysis,

Cite This: Yurddaskal M, Yıldırım S, Dikici T, Yurddaskal M, Erol M, Arıtman I, et al. ENHANCED PHOTOCATALYTIC PROPERTIES OF Sn-DOPED ZnO NANOPARTICLES BY FLAME SPRAY PYROLYSIS UNDER UV LIGHT IRRADIATION. Journal of the Turkish Chemical Society, Section A: Chemistry. 2018; 5(sp. is. 1):15-22.

Corresponding Author. E-mail: metin.yurddaskal@deu.edu.tr. 


\section{INTRODUCTION}

Doped or non-doped metal oxide nanostructures are preferred in the electronic materials category due to their superior physical, chemical and photocatalytic properties. Studies have demonstrated that broadband semiconductor photocatalysts such as ZnO can reduce various organic contaminants that offer great potential for completely removing toxic chemicals under UV radiation [Sun et al., 2011, Wu et al., 2011, Jia et al., 2011 and Al-Hadeethi et al., 2017]. In many photocatalytic reactions, ZnO has been reported to have high photocatalytic activity in the degradation of various organic contaminants in both acidic and basic media. The greatest advantage of $\mathrm{ZnO}$ is the absorption of more light quanta than other semiconductors by absorbing a larger portion of the UV spectrum [Postica et al., 2017, Kumar et al., 2016 and Ismail et al., 2016]. The suppression of recombination of photon-electron-hole pairs in semiconductors is necessary to increase the photocatalytic activity. Doping is a very useful way to improve load separation in semiconductor systems [Andolsi et al., 2017 and So et al., 2017]. In particular, tin (Sn) is considered one of the most important doping elements to improve the photocatalytic activity of $\mathrm{ZnO}$. Among the additive elements, $\mathrm{Sn}$ is compatible with the cage structure due to the similarity of ionic radius with zinc. As a result, $\mathrm{Sn}$ doping in $\mathrm{ZnO}$ is expected to affect the response or sensitivity of these materials for various gases [Aydin et al., 2015, Chahmat et al., 2014, Zegadi et al., 2014 and Li et al., 2012]. Different methods have been used in the literature for the synthesis of doped and undoped $\mathrm{ZnO}$ or other metal oxides; such as hydrothermal synthesis, sol-gel, solid state synthesis, liquid emulsion method, and magnetron sputtering. Flame spray pyrolysis (FSP) method is preferred method due to low grain size and homogeneous grain distribution compared to other production methods. Moreover, studying at low temperatures makes FSP safer and cheaper than solid state synthesis [Bae et al., 2005, Height et al., 2006, Salman et al., 2017 and Rherari et al., 2017]. In this study, Sn doped ZnO nanoparticles were easily produced by FSP. Structural, microstructural and photocatalytic properties of the produced nanoparticles were investigated and compared with the studies done in the literature and the results were evaluated.

\section{EXPERIMENTAL}

Undoped and $\mathrm{Sn}$-doped zinc oxide ( $\mathrm{ZnO}$ ) nanoparticles were produced by flame spray pyrolysis (FSP) equipment (Tethis, Np 10, Italy). The liquid precursor solution was fed into the flame from syringe pump with a feed rate of $5 \mathrm{ml} / \mathrm{min}$. The supporting methane/oxygen flow rate was kept constant with $5 \mathrm{l} / \mathrm{min}$ and oxygen/fuel ratio of 1.5/3. 
Undoped, 1, 3, 5, 7 and 9 at. \% Sn doped ZnO nanoparticles with diameters of below 200 $\mathrm{nm}$ were produced using this method.

Phase identification and crystal structures of the samples were performed by means of a Thermo Scientific ARL- Ka X-ray diffractometer (XRD). This instrument works with voltage and current settings of $45 \mathrm{kV}$ and $44 \mathrm{~mA}$, respectively. The $\mathrm{Cu}-\mathrm{Ka}$ has been used as the radiation source $(1.5405 \AA)$. Diffraction patterns were acquired in the range of $20^{\circ}$ to $70^{\circ}$ with a scanning rate of $2 \% \mathrm{~min}$. The surface morphology and microstructure of the samples were characterized by a scanning electron microscope (SEM, Zeiss Carl Ultra Plus).

To simulate the color change due to photocatalytic decomposition (color change of dye component such as methylene blue, MB), an experimental setup was established. $10^{-5} \mathrm{M}$ MB (Sigma Aldrich) and distilled water solution were prepared. Produced undoped and $\mathrm{Sn}$ doped $\mathrm{ZnO}$ nanoparticles were dispersed in this solution. The photodegradation of the MB experiments were practiced up to $180 \mathrm{~min}$. The distance between the light source and the suspension beaker was kept as $20 \mathrm{~cm}$. The absorption of the MB solutions was analyzed by a UV-1240 (Shimadzu) spectrophotometer based on the characteristic absorption of MB peak at $664 \mathrm{~nm}$.

\section{RESULTS AND DISCUSSION}

Figure 1 depicts the X-ray diffraction analysis (XRD) of the undoped and 1-9 at.\% Sn doped ZnO nanoparticles produced by FSP technique. It was observed that all peaks of the $\mathrm{ZnO}$ phases corresponding to $31.8,34.4,36.3,47.6,56.6,62.9$ and $67.9^{\circ}$ at $2 \theta$ values were assigned to (100), (002), (101), (102), (110), (103) and (201) of ZnO nanoparticles in accordance with the zincite pattern COD 9004180. These results indicate that the samples were polycrystalline wurtzite structure. No other peak for the cubic phases of $\mathrm{ZnO}$ or any other $\mathrm{ZnO}$ structures such as $\mathrm{ZnO}_{2}$ or $\mathrm{Zn}(\mathrm{OH})_{4}$ was seen and no characteristic peaks of any impurities were detected.

The surface morphology plays an important role in photocatalytic activity. Figure $2 \mathrm{a}$ and c illustrates structures of the nanoparticles in general view for undoped and $1 \% \mathrm{Sn}$ doped $\mathrm{ZnO}$, respectively. In addition, Figure $2 \mathrm{~b}$ and $\mathrm{d}$ represents the detailed structure and morphology of the nanoparticles with $200 \mathrm{k}$ magnification. In contrast to undoped ZnO nanoparticles, $1 \%$ Sn doped ZnO nanoparticles have higher surface area. It can be inferred that $\mathrm{Sn}$ doping into the $\mathrm{ZnO}$ at a certain amount improved the photocatalytic properties due to increasing surface area. 


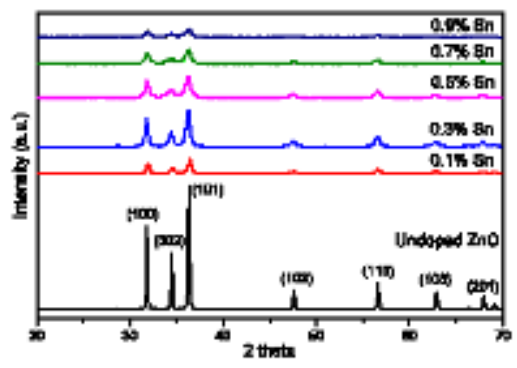

Figure 1: XRD patterns of the undoped and Sn doped ZnO nanoparticles produced by FSP.

(a)

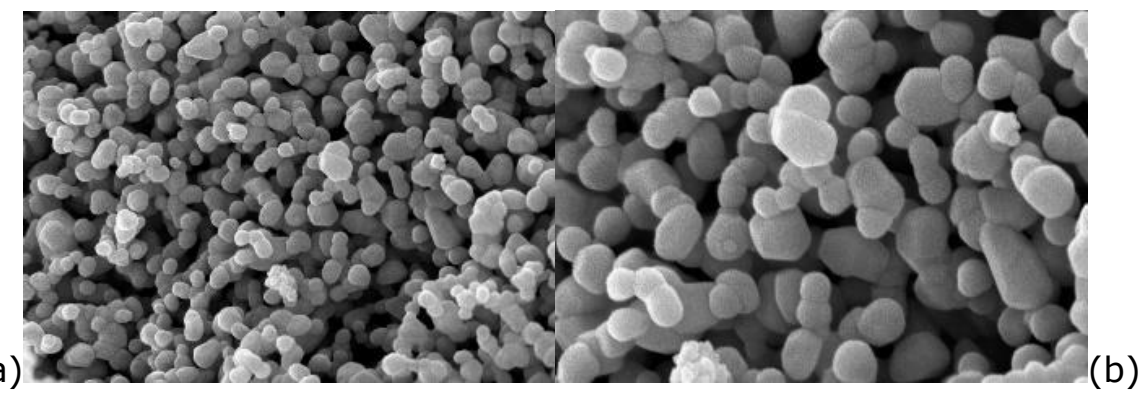

(c)

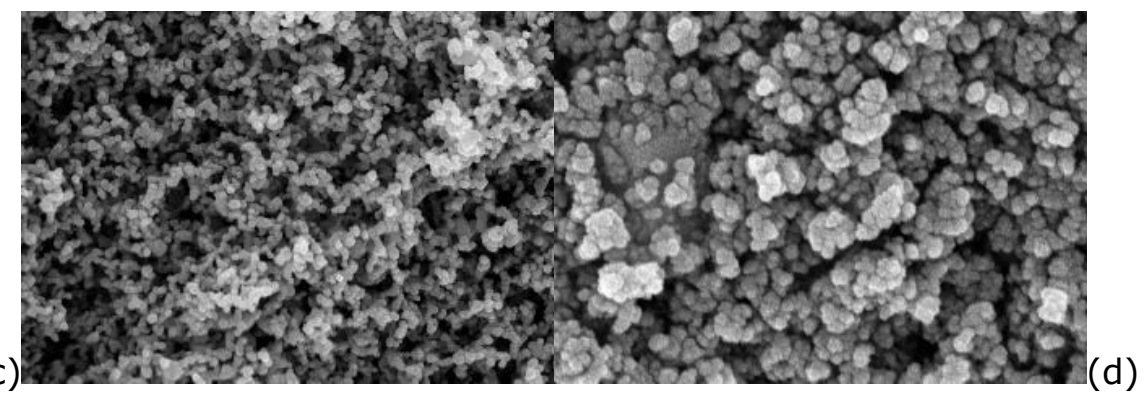

Figure 2: SEM images of the undoped and $1 \%$ at. Sn doped $\mathrm{ZnO}$ nanoparticles with low (a-c) and high magnifications (b-d). (a,c) $1 \mu \mathrm{m} .(b, d) 100 \mathrm{~nm}$.

As mentioned before, the MB dye was used to assess the photocatalytic performance of the undoped and \%1-9 Sn doped ZnO nanoparticles. Fig. 3 shows the photocatalytic degradation of MB by the produced nanoparticles. Considering the doping amount into the $\mathrm{ZnO}$ nanoparticles, the sample $1 \% \mathrm{Sn}$ doped $\mathrm{ZnO}$ has the best photocatalytic activity. $1 \% \mathrm{Sn}$ doped $\mathrm{ZnO}$ exhibited a very good photoactivity compared to all other samples. At the end of 180 minutes, MB was degraded more than $99 \%$ thanks to Sn doping into $\mathrm{ZnO}$. The degradation efficiency of the $0.1 \%$ Sn doped ZnO nanoparticles was $99.1 \%$, whereas that of the undoped $\mathrm{ZnO}$ nanoparticles was $61.3 \%$.

The degradation efficiency of the photocatalysts was given in Fig. 4. Further observation showed that photocatalytic activity gradually decreased with increasing amount of Sn in the nanoparticles. The $0.1 \% \mathrm{Sn}$ doped $\mathrm{ZnO}$ photocatalyst exhibited the highest 
photocatalytic activity for $180 \mathrm{~min}$. The increasing of the photocatalytic performance with $1 \%$ Sn doped $\mathrm{ZnO}$ can be explained by inhibition of recombination centers (Demirci et al., 2017).

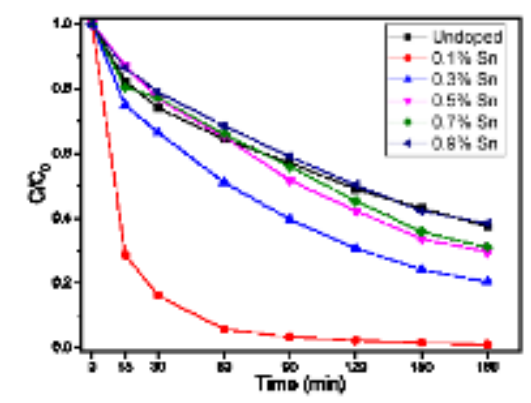

Figure 3: Photocatalytic degradations the undoped and Sn doped $\mathrm{ZnO}$ nanoparticles produced by FSP.

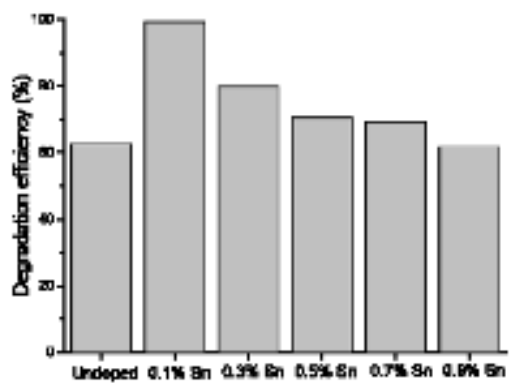

Figure 4: Photocatalytic efficiencies of the undoped and Sn doped ZnO nanoparticles produced by FSP.

\section{CONCLUSION}

In summary, undoped and Sn doped ZnO nanoparticles were produced by flame spray pyrolysis method successfully. The sample $1 \% \mathrm{Sn}$ doped $\mathrm{ZnO}$ is the best photocatalyst for degradation of MB. It was observed that the photocatalytic activity of $\mathrm{ZnO}$ nanoparticles increased after Sn doping, and the optimal Sn doped content was $1 \%$. With further increasing amount of $\mathrm{Sn}$, photocatalytic performance was gradually decreased. The best dopant concentration exhibiting maximum photocatalytic activity is explained based on space charge creation and rate of charge carrier recombination thanks to Sn doping into $\mathrm{ZnO}$. 


\section{REFERENCES}

Al-Hadeethi, Y., Umar, A., Al-Heniti, S. H., Kumar, R., Kim, S. H., Zhang, X., \& Raffah, B. M. (2017). 2D Sn-doped ZnO ultrathin nanosheet networks for enhanced acetone gas sensing application. Ceramics International, 43(2), 2418-2423.

Andolsi, Y., Chaabouni, F., \& Abaab, M. (2017). Sn doping effects on properties of ZnO thin films deposited by RF magnetron sputtering using a powder target. Journal of Materials Science: Materials in Electronics, 28(12), 8347-8358.

Aydin, H., El-Nasser, H. M., Aydin, C., Al-Ghamdi, A. A., \& Yakuphanoglu, F. (2015). Synthesis and characterization of nanostructured undoped and Sn-doped $\mathrm{ZnO}$ thin films via sol-gel approach. Applied Surface Science, 350, 109-114.

Bae, S. Y., Na, C. W., Kang, J. H., \& Park, J. (2005). Comparative structure and optical properties of Ga-, In-, and Sn-doped ZnO nanowires synthesized via thermal evaporation. The Journal of Physical Chemistry B, 109(7), 2526-2531.

Chahmat, N., Souier, T., Mokri, A., Bououdina, M., Aida, M. S., \& Ghers, M. (2014). Structure, microstructure and optical properties of Sn-doped $\mathrm{ZnO}$ thin films. Journal of Alloys and Compounds, 593, 148-153.

Demirci S., Dikici T., Yurddaskal M., Gultekin S., Toparli M., Celik E., Synthesis and characterization of $\mathrm{Ag}$ doped $\mathrm{TiO} 2$ heterojunction films and their photocatalytic performances Appl. Surf. Sci., 390 (2016), pp. 591-601.

Height, M. J., Mädler, L., Pratsinis, S. E., \& Krumeich, F. (2006). Nanorods of ZnO made by flame spray pyrolysis. Chemistry of Materials, 18(2), 572-578.

Ismail, A. S., Mamat, M. H., Sin, N. M., Malek, M. F., Zoolfakar, A. S., Suriani, A. B., \& Rusop, M. (2016). Fabrication of hierarchical Sn-doped ZnO nanorod arrays through sonicated sol-gel immersion for room temperature, resistive-type humidity sensor applications. Ceramics International, 42(8), 9785-9795.

Jia, X., Fan, H., Afzaal, M., Wu, X., \& O’Brien, P. (2011). Solid state synthesis of tin-doped ZnO at room temperature: characterization and its enhanced gas sensing and photocatalytic properties. Journal of hazardous materials, 193, 194-199.

Kumar, E. S., Mohammadbeigi, F., Boatner, L. A., \& Watkins, S. P. (2016). High resolution photoluminescence spectroscopy of Sn-doped ZnO single crystals. Journal of Luminescence, 176, 47-51.

Li, X., Chang, Y., \& Long, Y. (2012). Influence of Sn doping on ZnO sensing properties for ethanol and acetone. Materials Science and Engineering: C, 32(4), 817-821.

Postica, V., Hoppe, M., Gröttrup, J., Hayes, P., Röbisch, V., Smazna, D., ... \& Lupan, O. (2017). Morphology dependent UV photoresponse of Sn-doped ZnO microstructures. Solid State Sciences, 71, 75-86.

Rherari, A., Addou, M., Sofiani, Z., Jbilou, M., \& Diani, M. (2017). Effect of lithium on linear and nonlinear optical properties of $\mathrm{Sn-doped}$ zinc oxide prepared by spray pyrolysis. In IOP Conference Series: Materials Science and Engineering (Vol. 186, No. 1, p. 012002). IOP Publishing.

Salman, S. A., Hazza, S. Q., \& Abbas, S. J. (2017). Effect of Sn Doping on Structural and Electrical Properties of ZnO Thin Films Prepared by Chemical Spray Pyrolysis Method.

So, H. S., Hwang, S. B., Jung, D. H., \& Lee, H. (2017). Optical and electrical properties of Sndoped $\mathrm{ZnO}$ thin films studied via spectroscopic ellipsometry and hall effect measurements. Journal of the Korean Physical Society, 70(7), 706-713. 
Sun, J. H., Dong, S. Y., Feng, J. L., Yin, X. J., \& Zhao, X. C. (2011). Enhanced sunlight photocatalytic performance of Sn-doped ZnO for Methylene Blue degradation. Journal of Molecular Catalysis A: Chemical, 335(1), 145-150.

Wu, C., Shen, L., Yu, H., Huang, Q., \& Zhang, Y. C. (2011). Synthesis of Sn-doped ZnO nanorods and their photocatalytic properties. Materials Research Bulletin, 46(7), 1107-1112.

Zegadi, C., Abdelkebir, K., Chaumont, D., Adnane, M., \& Hamzaoui, S. (2014). Influence of Sn Low Doping on the Morphological, Structural and Optical Properties of ZnO Films Deposited by Sol Gel Dip-Coating. Advances in Materials Physics and Chemistry, 4(05), 93. 
